\title{
Prediction of Small-Strain Dynamic Properties on Granulated Spherical Glass Bead-Polyurethane Mixtures
}

\author{
Gyeong-o Kang, ${ }^{1}$ Woong Choi, ${ }^{2}$ and Changho Lee $\mathbb{D}^{2}$ \\ ${ }^{1}$ Honam Regional Infrastructure Technology Management Center, Chonnam National University, 50 Daehak-ro, Yeosu, \\ Jeollanam-do 59626, Republic of Korea \\ ${ }^{2}$ Department of Marine and Civil Engineering, Chonnam National University, 50 Daehak-ro, Yeosu, Jeollanam-do 59626, \\ Republic of Korea \\ Correspondence should be addressed to Changho Lee; changho@jnu.ac.kr
}

Received 1 July 2019; Revised 15 August 2019; Accepted 22 August 2019; Published 12 September 2019

Academic Editor: Eric Lui

Copyright (c) 2019 Gyeong-o Kang et al. This is an open access article distributed under the Creative Commons Attribution License, which permits unrestricted use, distribution, and reproduction in any medium, provided the original work is properly cited.

\begin{abstract}
This paper aims to propose predictive equations for the small-strain shear modulus $\left(G_{\max }\right)$ and small-strain damping ratio $\left(D_{\min }\right)$ of a granulated mixture with plastic and nonplastic materials to reduce the dynamic energy of the ground. Polyurethane bead (PB) and glass bead (GB) were used as the plastic and nonplastic materials, respectively. 180 resonant-column tests were conducted with various conditions affecting the dynamic properties, such as nonplastic particle content (PC), void ratio $(e)$, particle-size ratio $\left(s_{\mathrm{r}}\right)$, and mean effective confining pressure $\left(\sigma_{m}^{\prime}\right)$. The results showed that $G_{\max }$ and $D_{\min }$, respectively, increased and decreased as $e$ decreased with increasing $\sigma_{m}^{\prime}$ of material mixtures. In addition, $G_{\max }$ decreased with an increase in PC, whereas $D_{\min }$ increased. It was also found that $s_{\mathrm{r}}$ of materials affected the changes in $G_{\max }$ and $D_{\min }$. With an increase in $s_{\mathrm{r}}$, $G_{\max }$ increased while $D_{\min }$ decreased because small particles do not hinder the behavior of large particles as the size of larger particles increases. Finally, based on the results, new equations for estimating $G_{\max }$ and $D_{\min }$ of a granulated mixture with PB and GB were proposed as functions of PC, $e$, median grain size $\left(D_{50}\right)$, and $\sigma_{m}^{\prime}$.
\end{abstract}

\section{Introduction}

Dynamic soil properties, such as shear modulus $(G)$ and material damping ratio $(D)$, have been used as key parameters for evaluating seismic ground response and design of foundation subjected to cyclic or dynamic loading. The behavior of these parameters varies with shear-strain amplitude beyond the specific threshold value of shear strain. In other words, both $G$ and $D$ exhibit linear behavior at a very small strain level, whereas nonlinear behavior with increasing shear strain. $G$ and $D$ at very small strain amplitudes $\left(10^{-3} \%\right)$ are referred to as the small-strain shear modulus $\left(G_{\max }\right)$ and the small-strain damping ratio $\left(D_{\min }\right)$.

There are two ways to reduce the dynamic energy of the ground and to prevent damage from the earthquake. The first way is to increase $G$, and the other is to increase $D$ [1-21]. The factors affecting dynamic soil behavior include shear strain $(\gamma)$, mean effective confining stress $\left(\sigma_{m}^{\prime}\right)$, void ratio $(e)$, plasticity index $(\mathrm{PI})$, soil grain distribution, degree of saturation, frequency of loading, and the number of cycles. Its relation is quite complicated because these factors vary depending on the soil type and the ground conditions. Wichtmann et al. [20] and Choo and Burns [21] studied the dynamic properties according to differences in fine content. They suggested that $G_{\max }$ is reduced by an increase in the fine content, in a way that depends on the specific fine content and particle-size ratio. Santamarina et al. [15] performed a theoretical analysis of packing of granular mixtures of different-sized particles because the shear wave velocity $\left(V_{s}\right)$ or $G_{\max }$ in a medium of material is dependent on packing arrangement and packing density. They demonstrated that the maximum size of small particles that can be placed in the pore between large particles is different according to packing conditions such as loose and dense packing. 
The dynamic properties of heterogeneous materials mixed with a plastic material, such as a rubber by-product, have been studied to investigate the absorption of earthquake vibrations and the reduction of seismic forces [22-26]. They reported that soil-rubber mixtures reduce $G_{\max }$ as rubber content increases for all $\sigma_{m}^{\prime}$, whereas $G_{\max }$ increases as $\sigma_{m}^{\prime}$ increases. $D$ was generally increased by an increase in rubber content but decreased with $\sigma_{m}^{\prime}$. Although many researchers have studied the various factors affecting the dynamic soil behavior, there are still few studies on the dynamic property of mixtures of different types of materials that use the plastic material to reduce the dynamic energy.

The objective of this study is to investigate the dynamic properties of mixtures composed of plastic and nonplastic materials that are used to reduce the dynamic energy of the ground. The resonant column (RC) test was carried out with various polyurethane content $(\mathrm{PC})$, void ratio $(e)$, particle ratio $\left(s_{\mathrm{r}}\right)$, and mean effective confining stress $\left(\sigma_{m}^{\prime}\right)$. New models based on various factors, such as PC, $e$, median grain size $\left(D_{50}\right)$, and $\sigma_{m}^{\prime}$, are introduced to predict $G_{\max }$ and $D_{\min }$ of the mixture.

\section{Previous Empirical Equations for Estimating $G_{\max }$ and $D_{\min }$}

To calculate $G_{\max }$ and $D_{\min }$, the measurement of shear wave velocity $\left(V_{s}\right)$ in the field and laboratory has usually been conducted using the cyclic direct shear test and RC tests, respectively. However, since these methods are both costly and time-consuming, it is difficult to use them in the design of small projects with a small budget. Hence, an empirical equation for predicting the dynamic soil properties such as $G_{\max }$ and $D_{\min }$ might be useful for preliminary design, design calculation of small project, and confirmation of the observed values $[18,27]$.

An empirical equation to predict $G_{\max }$ on cohesionless soils proposed by Hardin and Richart [28] has been widely used as

$$
G_{\max }=A \frac{(a-e)^{2}}{(1+e)}\left(\frac{p}{p_{\mathrm{atm}}}\right)^{n} p_{\mathrm{atm}}
$$

where $e=$ void ratio; $p=$ mean pressure; $p_{\text {atm }}=$ atmospheric pressure $(100 \mathrm{kPa}) ; A, a$, and $n$ are constants $(A=690$, $a=2.17$ and $n=0.5$ for round grains, and $A=320, a=2.97$ and $n=0.5$ for angular grains). Some researchers have also proposed formulas to predict $G_{\max }$ based on a function of the void ratio similar to Hardin's formula [29-31]. Wichtmann and Triantafyllidis [18] proposed a formula that correlates Hardin's formula with uniformity coefficient $\left(C_{\mathrm{u}}\right)$ to examine the influence of the grain-size distribution on $G_{\max }$. Choo and Burns [21] introduced the critical fine content $\left(\mathrm{FC}^{*}\right)$ and intergranular void ratio $\left(e_{\mathrm{ig}}\right)$ to evaluate the property of shear wave velocity on packing of a granular mixture composed of large and small silica particle sizes. In addition, empirical formulas for estimating $G_{\max }$ considering the effects of $\sigma_{m}^{\prime}$ and rubber content on rubber-sand mixture were proposed $[26,32]$.
Most empirical formulas for estimating $D$ are composed of a relation of $G / G_{\max }$ based on assuming that $D$ value is proportional to $1-\left(G / G_{\max }\right)[33,34]$. In addition, other equations were expressed by a polynomial formula $[10,35,36]$. Zhang et al. [17] proposed a formula related to $D_{\text {min }}$ considering PI and $\sigma_{m}^{\prime}$, and the polynomial formula for estimating $D$ based on $D-D_{\min }$ and $G / G_{\max }$ was expressed as

$$
D-D_{\min }=a_{1}\left(\frac{G}{G_{\max }}\right)^{2}-a_{2}\left(\frac{G}{G_{\max }}\right)+a_{3},
$$

where $a_{1}, a_{2}$, and $a_{3}=$ constants $\left(a_{1}=9.4, a_{2}=26.5\right.$ and $a_{3}=17.1$ for RC test, and $a_{1}=10.6, a_{2}=31.6$, and $a_{3}=21.0$ for torsional shear test).

According to literature, previous empirical equations to predict $G_{\max }$ can be overestimated or underestimated depending on the characteristics of the materials and type of test. In addition, there are very few empirical equations to predict $D_{\min }$ for heterogeneous mixtures using plastic and nonplastic materials such as rubber and sand to reduce the seismic forces and earthquake vibration. Moreover, $G_{\max }$ in most cases of proposed equations has been used as a reference value to estimate $D_{\text {min }}$ of soils. Although some researchers have studied the equations of dynamic properties for mixtures according to different particle sizes $[20,21]$, there is a dearth of studies on the empirical equation to predict the dynamic properties considering the significant factors, such as $\sigma_{m}^{\prime}, \mathrm{FC}, e$, and $D_{50}$, for the binary mixtures composed of both plastic and nonplastic materials.

\section{Experimental Program}

3.1. Materials and Sample Preparation. Spherical glass bead (GB) and polyurethane bead (PB) of single particle sizes were selected to remove the particle shape from among the variables that might affect the dynamic properties. These non-cohesive materials were used to effectively control the particle-size ratio $\left(s_{\mathrm{r}}=d_{\mathrm{L}} / d_{\mathrm{S}}\right.$, where $d_{\mathrm{L}}$ is the median grain size of large particles $(\mathrm{GB})$ and $d_{\mathrm{S}}$ is the median grain size of small particles (PB)). GB and $\mathrm{PB}$ were purchased from B\&K MEDIA Co, Ltd., and Doosung Chemis Co, Ltd., respectively. GB was prepared as five types in terms of particle size in order to consider the effect of particle size on the values of $d_{\mathrm{L}} / d_{\mathrm{S}}$, and $\mathrm{PB}$ was used at a fixed size. The physical properties of the materials and the composition ratios of the samples are listed in Tables 1 and 2, respectively. The PB contents (PC) can be defined as the ratio of the volume of $\mathrm{PB}$ particles to the volume of the total mixture, with GB and PB given by

$$
\mathrm{PC}=\frac{V_{\mathrm{PB}}}{V_{\mathrm{GB}}+V_{\mathrm{PB}}} \times 100(\%),
$$

where $V_{\mathrm{PB}}$ and $V_{\mathrm{GB}}$ are the volumes of $\mathrm{PB}$ particles and GB particles, respectively.

The grain-size distributions for each material are shown in Figure 1, from which one can observe that materials used are generally of single particle size. For the preparation of 
Table 1: Physical properties of GB and PB.

\begin{tabular}{lccccc}
\hline Properties & PB & GB 100 & GB 250 & GB 400 & GB 600 \\
\hline Median grain size $\left(D_{50}(\mathrm{~mm})\right)$ & 0.08 & 0.09 & 0.13 & 0.23 & 0.34 \\
Specific gravity $\left(G_{s}\right)$ & 1.05 & & & 2.48 & 0.51 \\
Coefficient of uniformity $\left(c_{\mathrm{u}}\right)$ & 1.52 & 1.62 & 1.22 & 1.09 & 1.34 \\
Coefficient of curvature $\left(c_{\mathrm{c}}\right)$ & 1.30 & 1.20 & 0.97 & 0.98 & 0.96 \\
Minimum void ratio $\left(e_{\min }^{1}\right)$ & 0.32 & & & 0.55 & 0.97 \\
Maximum void ratio $\left(e_{\max }^{1}\right)$ & 0.51 & & 0.69 & \\
\hline
\end{tabular}

${ }^{1}$ Same value independent of GB particles.

TABle 2: Composition ratio of mixtures.

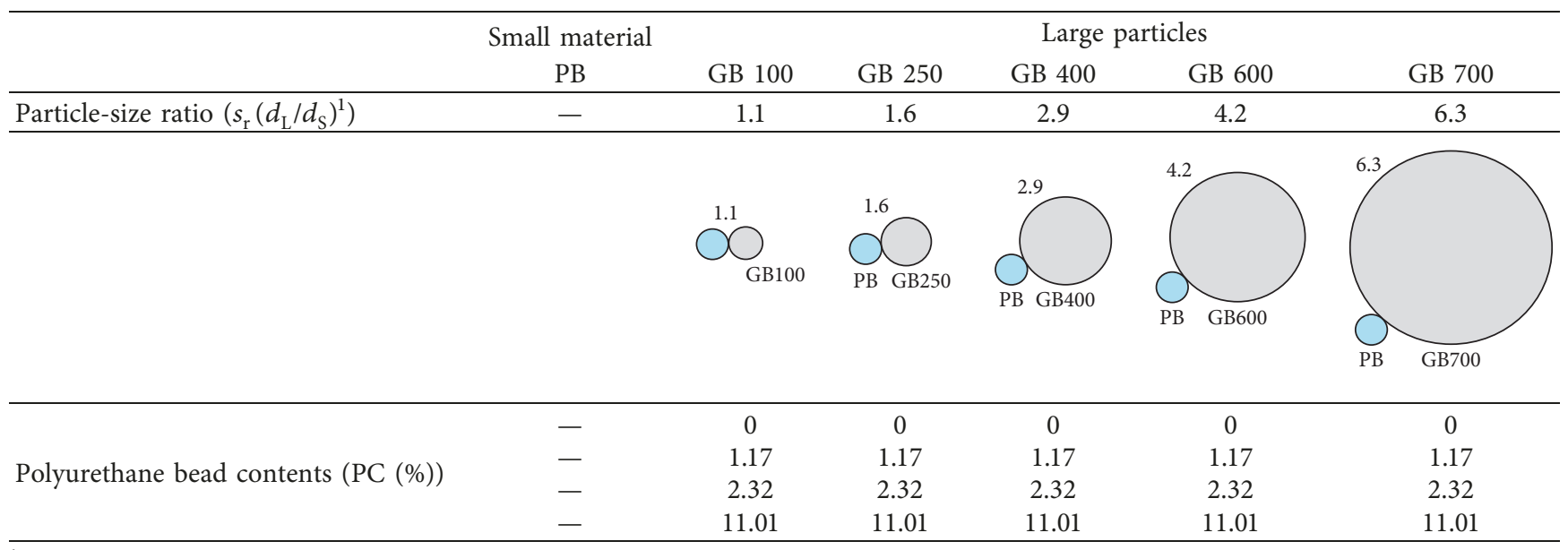

${ }^{1}$ Particle-size ratio that is defined as the ratio of median grain size of GB to the median grain size of PB.

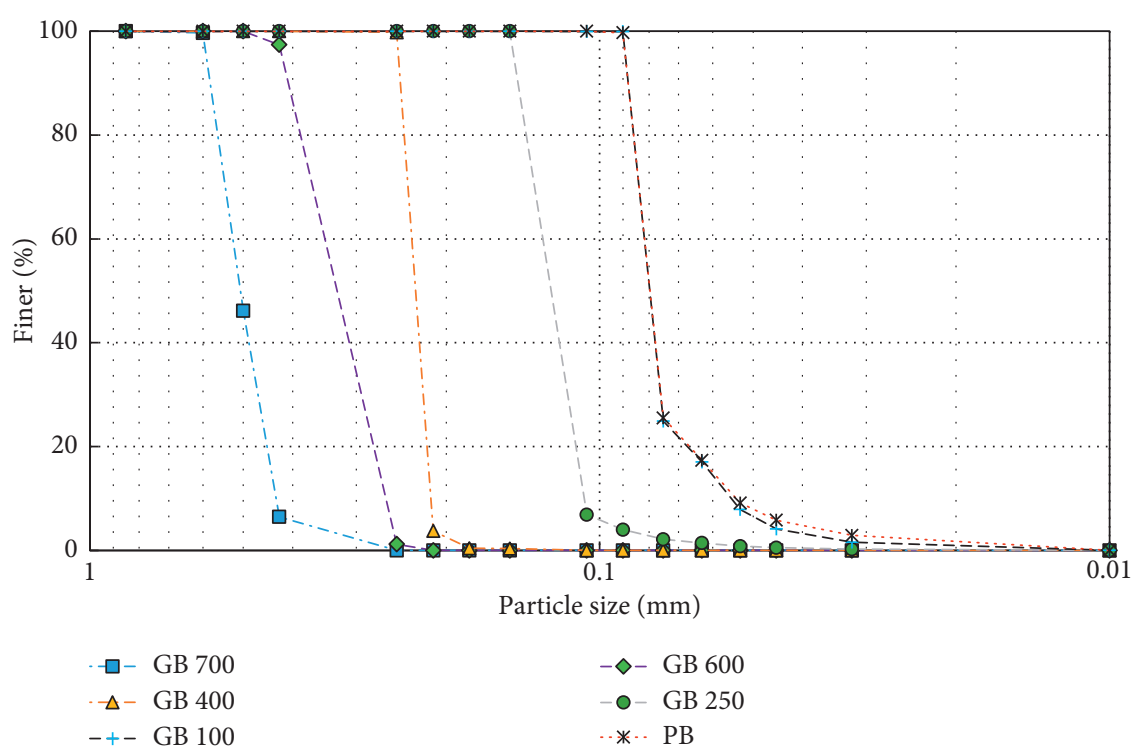

FIGURE 1: Grain size distribution of tested materials.

the RC test samples, GB and PB particles were thoroughly mixed for $5 \mathrm{~min}$. Predetermined weight of mixture for each relative density condition was used to prepare the samples. The mixtures were poured into the mold by the air pluviation method with extra caution to minimize the segregation of the mixture. The same compactive energy was lightly applied to each layer for obtaining the target density.
The sample size is approximately $51 \mathrm{~mm}$ in diameter and $105 \mathrm{~mm}$ in height.

3.2. Experimental Setup and Procedure. In this study, the RC test was carried out to obtain the dynamic characteristics, $G_{\max }$ and $D_{\min }$. Stokoe-type device is a fixed-free system, and 
TABle 3: Experimental condition.

\begin{tabular}{|c|c|c|c|c|c|c|}
\hline \multirow{2}{*}{ Type } & \multirow{2}{*}{$\begin{array}{c}\text { Small material } \\
\text { PB }\end{array}$} & \multicolumn{5}{|c|}{ Large particles } \\
\hline & & GB 100 & GB 250 & GB 400 & GB 600 & GB 700 \\
\hline Particle-size ratio $\left(s_{\mathrm{r}}\left(d_{\mathrm{L}} / d_{\mathrm{S}}\right)\right)$ & - & 1.1 & 1.6 & 2.9 & 4.2 & 6.3 \\
\hline \multirow{3}{*}{ Confining pressure $\left(\sigma_{m}^{\prime}(\mathrm{kPa})\right)$} & \multirow{3}{*}{-} & 100 & 100 & 100 & 100 & 100 \\
\hline & & 200 & 200 & 200 & 200 & 200 \\
\hline & & 300 & 300 & 300 & 300 & 300 \\
\hline \multirow{3}{*}{ Relative density $\left(D_{\mathrm{r}}(\%)\right)$} & \multirow{3}{*}{ - } & 40 & 40 & 40 & 40 & 40 \\
\hline & & 60 & 60 & 60 & 60 & 60 \\
\hline & & 80 & 80 & 80 & 80 & 80 \\
\hline
\end{tabular}

the top is freely rotatable. The RC device consists mainly of confining pressure control system, excitation system, and displacement measurement system. All tests were performed in a dry condition under different relative densities, confining pressure, and particle-size ratio, as summarized in Table 3. The sample is placed inside the membrane in a pressure cell, and then predetermined confining pressure is applied to the sample as the isotropic condition for $20 \mathrm{~min}$. RC tests were conducted with various shear strain magnitudes. In this study, the change of the sample height was monitored by using a proximitor to measure the volume change of the sample caused by the confining pressure. Based on the elastic-wave theory, the shear modulus was calculated by the shear wave velocity obtained from the resonant frequency. The damping ratio was calculated by the free-vibration decay method.

\section{Results and Discussion}

4.1. Factors Affecting $G_{\max }$ of the Mixture. Based on the previous studies, we could propose a multiplicative model to predict $G_{\max }$ of a spherical material mixture as

$$
G_{\max }(\mathrm{MPa})=(A+f(\mathrm{PC})) \cdot f(e) \cdot\left(\sigma_{m}^{\prime}\right)^{n},
$$

where $A=G_{\max }$ of materials with no influence of void ratio when $\sigma_{m}^{\prime}$ is $1 \mathrm{kPa} ; f(\mathrm{PC})=$ function of effect of $\mathrm{PC}$ on $G_{\max }$ in mixtures; $f(e)=$ function of effect of $e$ on $G_{\max }$ in mixtures (packing function); $n=$ sensitivity of the curve of $\mathrm{G}_{\max }$ depending on $\sigma_{m}^{\prime}$.

4.1.1. Effect of Packing (e) on $G_{\max }$. Choo and Burns [21] reported that the behavior of $G_{\max }$ of the mixture cannot be expressed by a global void ratio (e) that defines the ratio of the volume of voids to volumes of small and large particles because $e$ does not capture the mechanical behavior of large particles with smaller particles that are fully filled in the void formed by large particles. Therefore, intergranular void ratio $\left(e_{\mathrm{ig}}\right)$ was defined by the ratio of the volumes of voids and small particles to the volume of large particles. In this study, $e_{\text {ig }}$ was used to consider the mechanical behavior of large particles with small particles that are completely filled in the void between large particles. Figure 2 shows the effect of the void ratios (i.e., $e$ and $e_{\text {ig }}$ ) in GB-PB spherical mixtures. The relation of $G_{\max }$ and $e$ showed no clear trend with a large dispersion. On the other hand, $G_{\max }$ tended to decrease with an increase of $e_{\text {ig }}$ and PC and to increase with an increase of $s_{\mathrm{r}}$ because $\mathrm{PB}$ has a small stiffness relative to GB. It means that the small particle (PB) hinders the behavior of large particles (GB). As shown in Figure 2, $e_{\mathrm{ig}}$ agreed well with $G_{\max }$ compared to the relationship between $e$ and $G_{\max }$. Consequentially, we used the equation for the effect of the void ratio on $G_{\max }$ by using the packing function for round particles suggested by Hardin and Richart [28] and $e_{\mathrm{ig}}$ as

$$
f(e)=f\left(e_{\mathrm{ig}}\right)=\frac{\left(E-e_{\mathrm{ig}}\right)^{2}}{1+e_{\mathrm{ig}}},
$$

where $E$ is the constant of packing for round particle and its value is 2.17 [28].

4.1.2. Effect of Confinement $\left(\sigma_{m}^{\prime}\right)$ on $G_{\max }$. The value of $G_{\max }$ in GB normalized by the packing function with $e_{\text {ig }}$ for the round particles, as proposed by Hardin and Richart [28], was used in order to examine $G_{\max }$ of spherical mixtures when $\sigma_{m}^{\prime}$ was 100,200 , and $300 \mathrm{kPa}$. Figure 3 shows the relationship between the $G_{\max }$ normalized by $f\left(e_{\text {ig }}\right)$ and $\sigma_{m}^{\prime}$ for pure $\mathrm{GB}$ (i.e., $\mathrm{PC}=0 \%$ ). All normalized values of $\mathrm{GB}$ increased with an increase of confining pressure independent of the size of the material. The relation between normalized $G_{\max }$ and $\sigma_{m}^{\prime}$ shows a power function similar to Hardin and Richart's equation (1), depended on the particle-size ratio $\left(s_{\mathrm{r}}\right)$. Therefore, it is necessary to confirm the influence of the median particle size of $\mathrm{GB}\left(D_{50 \mathrm{~GB}}\right)$ on the value of exponent $n$. The relationship between $n_{\text {pureGB }}$ and $D_{50}$ for pure GB is plotted in Figure 4(a), which shows that $n_{\text {pureGB }}$ increased with an increase of $D_{50 \mathrm{~GB}}$ as $n_{\text {pureGB }}=a \cdot D_{50 \mathrm{~GB}}^{b}$. Furthermore, for verifying the change of $n$ in terms of the plastic particle contents, $n$ is plotted with the changes for PC and $s_{\mathrm{r}}$ contents, as shown in Figure 4(b). The $n$ tended to increase linearly with a constant slope as PC increased, regardless of $s_{\mathrm{r}}$, and its equation was obtained as $n=c \cdot \mathrm{PC}+n_{\text {pureGB }}$. The values of these parameters change with the difference in $s_{\mathrm{r}}$. Consequently, the exponent $n$ can be determined by considering the effects of $D_{50 \mathrm{~GB}}$ and PC as

$$
n=c \cdot \mathrm{PC}+a \cdot D_{50 \mathrm{~GB}}^{b}
$$

where $a$ and $b$ are 0.6 and 0.06 , respectively. $c$ is the gradient for the relationship between $n$ and PC, and its value is 0.01 in this study. 


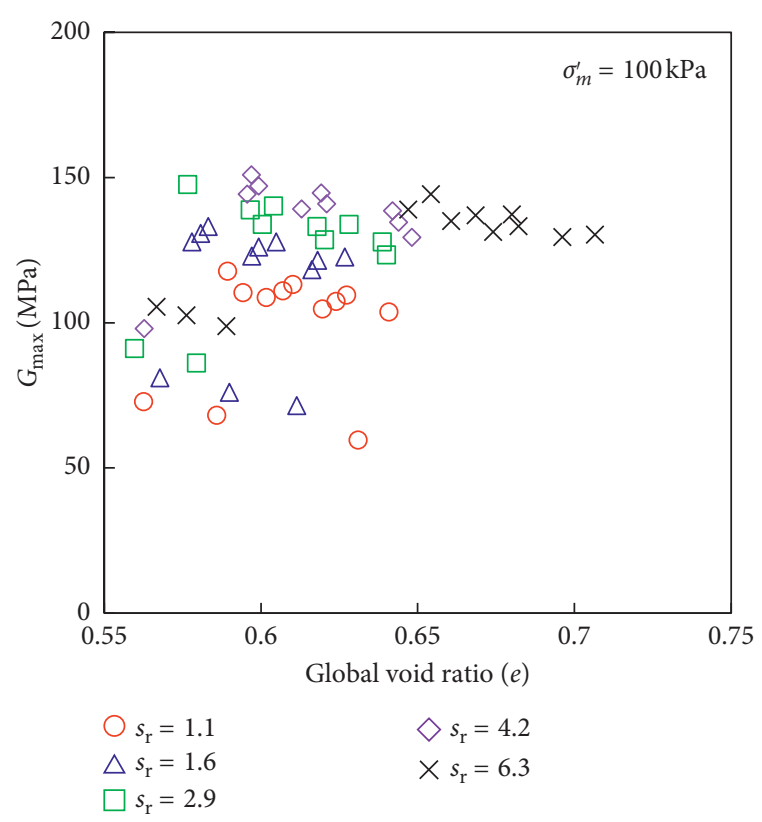

(a)

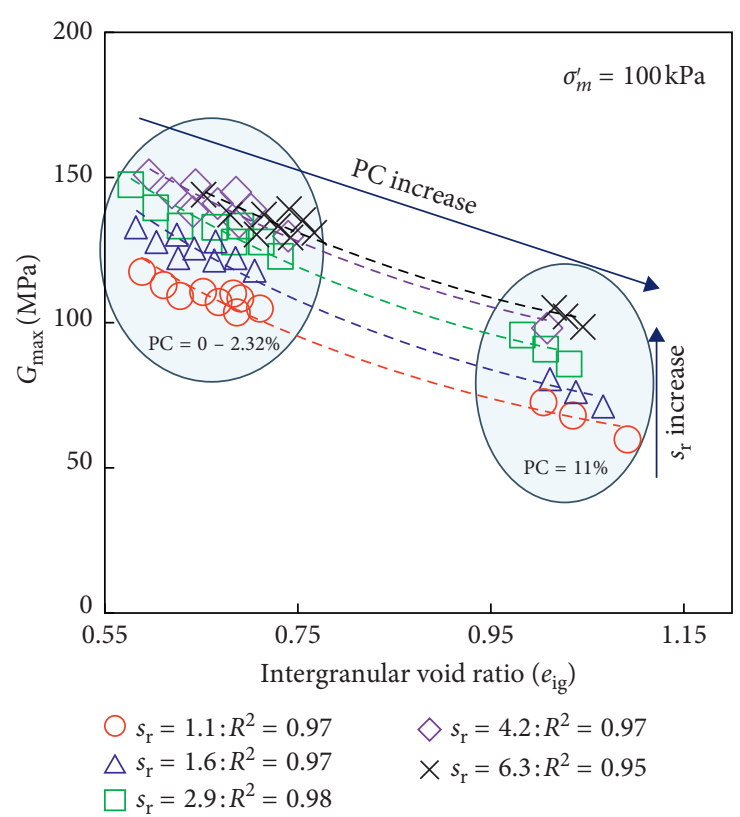

(b)

Figure 2: Relation of $G_{\max }$ with (a) global void ratio $e$ and (b) intergranular void ratio $\left(e_{\mathrm{ig}}\right)$.

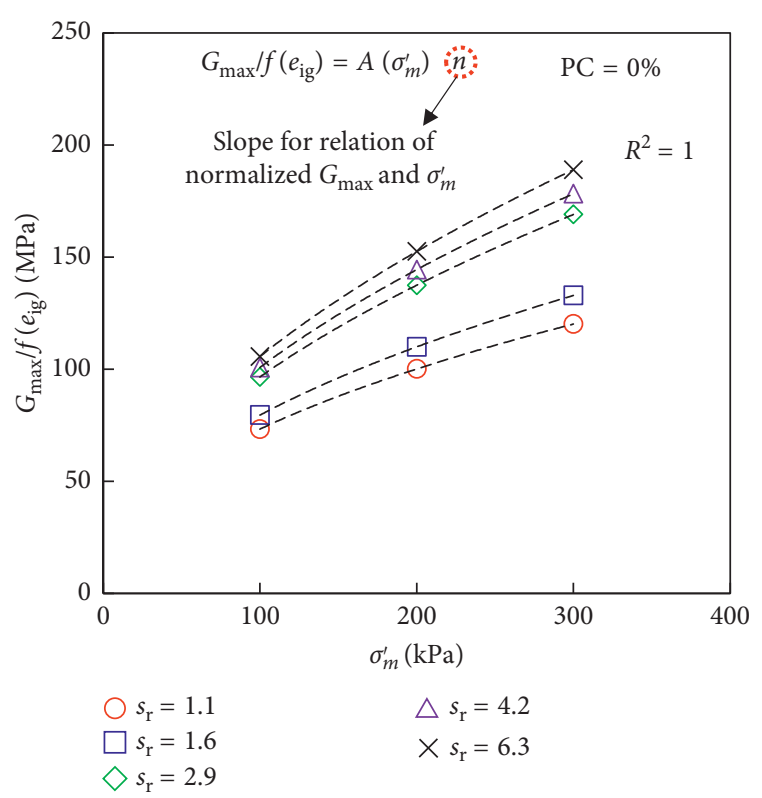

FIGURE 3: Relation between $G_{\max } / f\left(e_{\mathrm{ig}}\right)$ and $\sigma_{m}^{\prime}$.

4.1.3. Effects of Size Ratio $\left(s_{r}\right)$ and $P B$ Content $(P C)$ on $G_{\max }$. The coefficient $A$ in equation (4) represents the $G_{\max }$ of the main materials with no influences by the void ratio and the confining pressure. Figure 5 shows $G_{\max }-f\left(e_{\mathrm{ig}}\right)$ curve with the changes of $s_{\mathrm{r}}$ when $\sigma_{m}^{\prime}=1 \mathrm{kPa}$. An experiment was carried out by changing the diameter of the pure GB mixture (i.e., $\mathrm{PC}=0 \%$ ) to evaluate the $G_{\max }$ of mixtures according to $s_{\mathrm{r}}$. The value of $G_{\max }-f\left(e_{\mathrm{ig}}\right)$ when the $\sigma_{m}^{\prime}=1 \mathrm{kPa}$ converged to approximately 7.2 MPa for all $s_{\mathrm{r}}$ conditions in this study, as shown in Figure 5. It implies that $s_{\mathrm{r}}$ affects only the slope of the change curve with increasing confining pressure without affecting other factors.
The relationship between the first term $(A+f(\mathrm{PC}))$ and PC is plotted in Figure 6 to access the $G_{\max }$ of mixtures with the change of PC at $\sigma_{m}^{\prime}=1 \mathrm{kPa}$. It was observed that $G_{\max }$ linearly decreased with an increase of PC, and its gradient is -58.85 in this study as follows:

$$
f(\mathrm{PC})=d \cdot \mathrm{PC}=-58.85 \cdot \mathrm{PC} \text {. }
$$

4.2. Factors Affecting $D_{\min }$ of the Mixture. $D_{\text {min }}$ of a spherical material mixture is affected by the properties of the material, void ratio, plastic index, and confining pressure $[25,26]$. In this study, estimating formula for $D_{\text {min }}$ of a spherical material mixture was established as follows based on the literature:

$$
D_{\text {min }}=\left(\alpha+f(\mathrm{PC})_{D_{\min }}\right) \cdot f(e)_{D_{\min }}(e) \cdot\left(\sigma_{m}^{\prime}\right)^{\beta},
$$

where $\alpha=D_{\text {min }}$ of the material without the influence of void ratio when $\sigma_{m}^{\prime}$ is $1 \mathrm{kPa} ; f(\mathrm{PC})_{D_{\min }}=$ function of effect of PC on $D_{\text {min }}$ in mixtures; $f(e)_{D_{\min }}=$ function of effect of $e$ on $D_{\text {min }}$ in mixtures (packing function); $\beta=$ sensitivity of the curve of $D_{\min }$ depending on $\sigma_{m}^{\prime}$.

$D_{\text {min }}$ was insufficient to investigate the effect of the packing function, especially for heterogeneous materials. Therefore, it is necessary to normalize the measured $D_{\min }$ value with the packing function to accurately analyze the influence of each factor on the proposed $D_{\min }$ model. Note that, in this study, the packing function, $\left(f(e)_{D_{\min }}\right)$, at which the void ratio affects $D_{\min }$, adopted the same form on the $G_{\max }$ model proposed by Hardin and Richart [28], in equation (5). However, the constant corresponding to the shape factor in the packing function should be calculated to apply Hardin's packing function for $D_{\min }$. The shape factor was determined using multivariable regression analysis for 


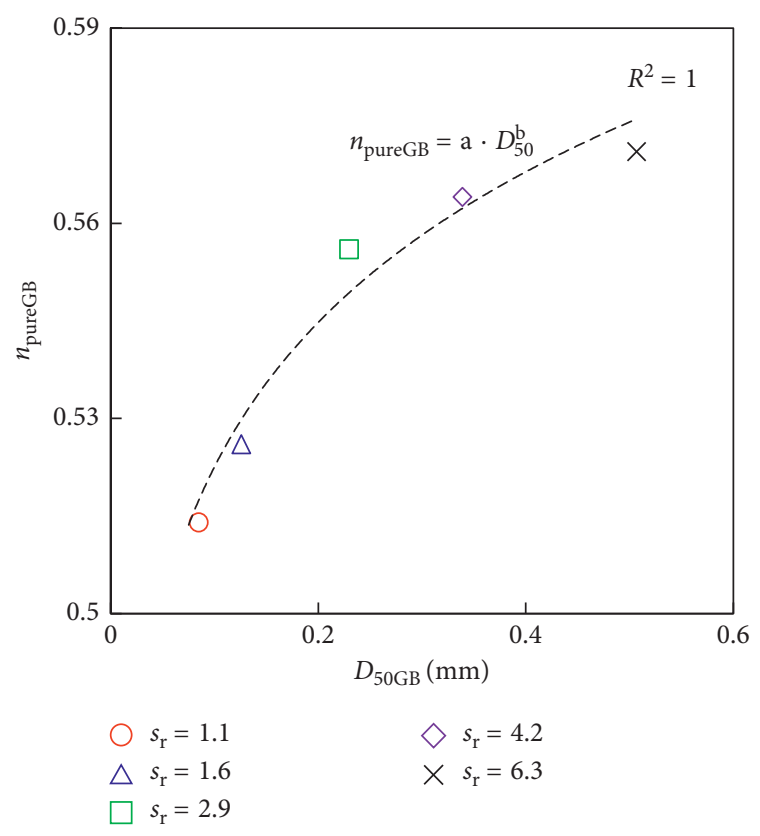

(a)

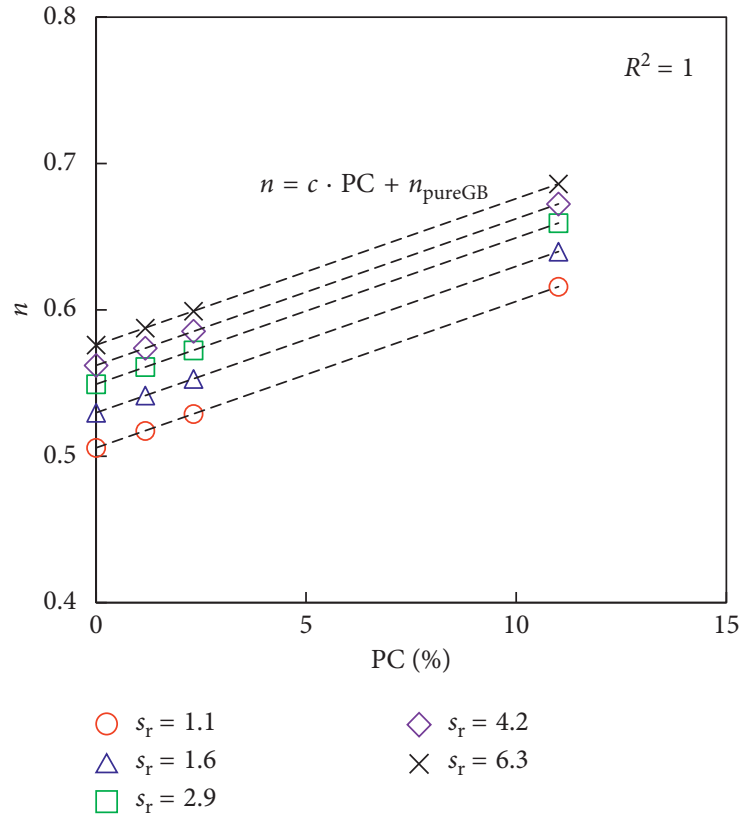

(b)

FIGURE 4: Variation of $n$ exponent according to (a) effect of median particle size of GB $\left(D_{50 \mathrm{~GB}}\right)$ and (b) effect of PC content.

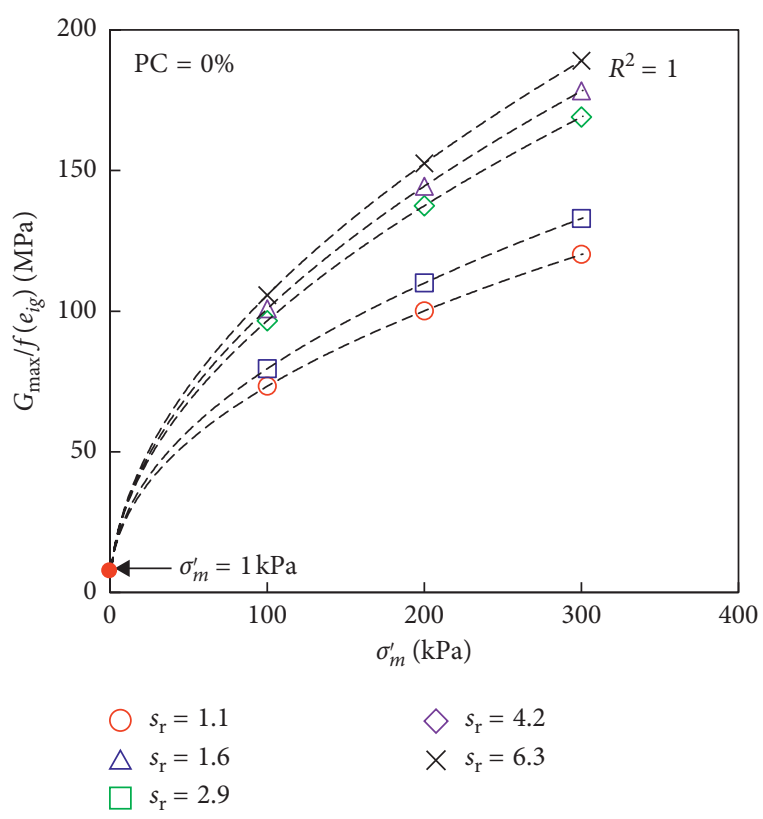

Figure 5: Relation between $G_{\max } / f\left(e_{\mathrm{ig}}\right)$ and various $s_{\mathrm{r}}$.

each test condition. The $e, \sigma_{m}^{\prime}$, and PC were used as the independent variables for each measured $D_{\min }$ values in order to estimate the shape factor.

Consequently, the value of the shape factor was presumed approximately 0.04 based on the multivariable analysis study, and the packing function of $D_{\min }$ model can be expressed as

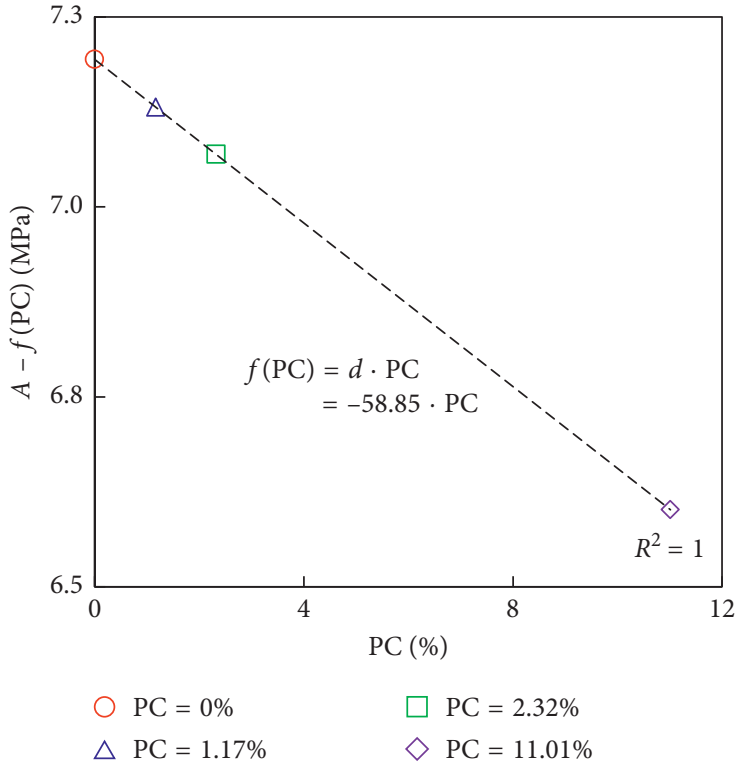

Figure 6: Relation between $A-f(\mathrm{PC})$ and various PC.

$$
D_{\min }: f(e)_{D_{\min }}=\frac{(C-e)^{2}}{(1+e)}=\frac{(0.04-e)^{2}}{(1+e)}
$$

Note that, in this study, each variable affecting $D_{\min }$ in the proposed model was established by the fixed packing function. Additionally, the reliability of the proposed packing function was verified by inversely estimating the constant of the shape factor based on the calculated variable. 


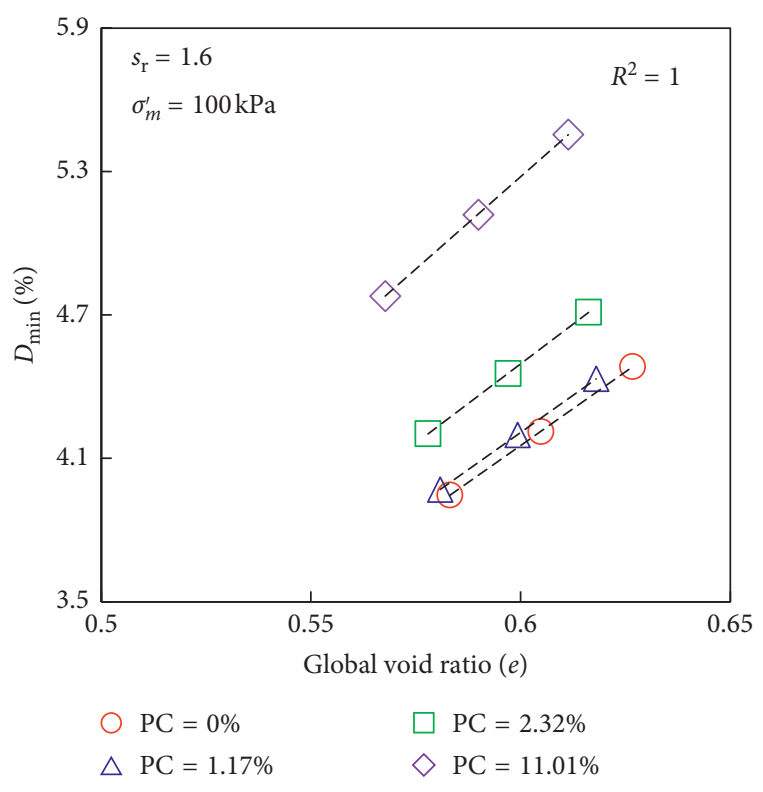

(a)

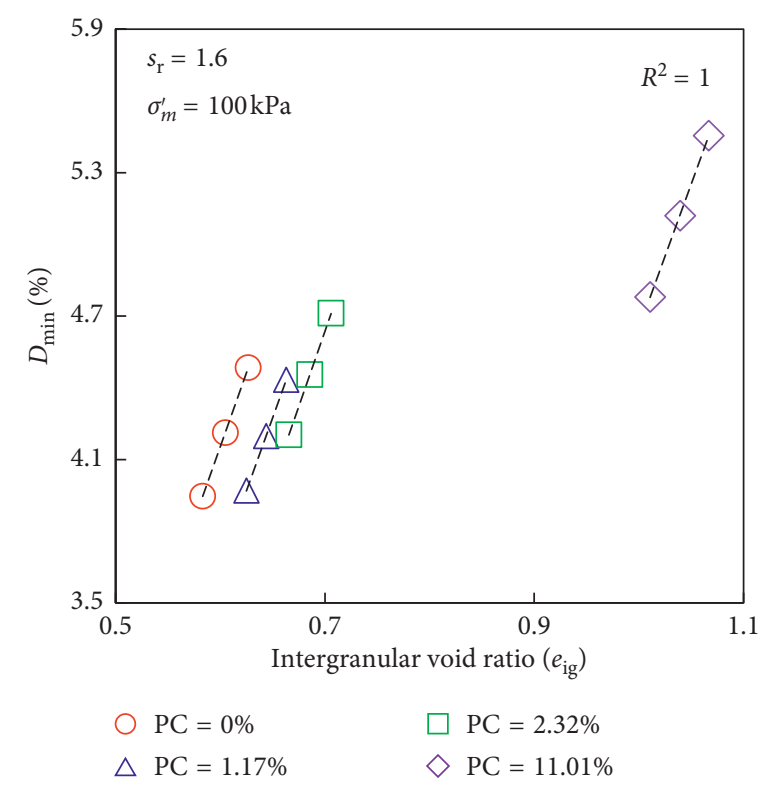

(b)

Figure 7: Variation of $D_{\text {min }}$ with (a) global void ratio $e$ and (b) intergranular void ratio $\left(e_{\text {ig }}\right)$.

4.2.1. Effect of Packing (e) on $D_{\min }$. Representative $D_{\min }$ value for $s_{\mathrm{r}}=1.6$ and $\sigma_{m}^{\prime}=100 \mathrm{kPa}$ are plotted along with $e$ and $e_{\text {ig }}$ in Figure 7 to investigate the influence of the void ratio on $D_{\min }$. As shown in Figure 7, $D_{\min }$ increased with an increase of the void ratio under the equal condition of PC because the stiffness decreases when the mixture is loose and the behavior of large particles is impeded by increase of the soft and elastic materials, such as PB; the larger the PC, the larger the $D_{\min }$. Consequently, $D_{\min }$ could be increased by increasing the plasticity. It can be observed in Figure 7 that both $e$ and $e_{\mathrm{ig}}$ work in the same manner on $D_{\min }$ based on the result. However, for $D_{\min }$, it was reasonable to suggest a model with $e$ rather than $e_{\mathrm{ig}}$ in term of $f(e)$ because both the large and small particles participate in the $D_{\min }$ of the whole mixture. Therefore, the packing function $(f(e))$ composed of $e$ and the shape factor for affecting the void ratio on $D_{\min }$ was proposed in this study as equation (9).

4.2.2. Effect of Confinement $\left(\sigma_{m}^{\prime}\right)$ on $D_{\min }$. The value of $D_{\min }$ in pure GB material normalized by the packing function proposed in this study with $e$ was plotted in Figure 8 against the change of $\sigma_{m}^{\prime}$ to 100,200 , and $300 \mathrm{kPa}$, to assess the effect of $\beta$ on $D_{\min }$. $D_{\min }$ of all mixtures decreased with an increase in $\sigma_{m}^{\prime}$, and $\beta$, which is the sensitivity of $D_{\min } / f(e)_{D_{\min }}$, decreased with an increase of $s_{\mathrm{r}}$. The $\beta$ exponent according to $D_{50 \text { GB }}$ of pure GB material is plotted in Figure $9(a)$ in order to verify the variation of $D_{50 \mathrm{~GB}}$, not $s_{\mathrm{r}}$. The $\beta$ value tends to exponentially decrease with an increase of $D_{50 \mathrm{~GB}}$ as $\beta_{\text {pureGB }}=-\gamma \cdot \ln D_{50 \mathrm{~GB}}$. Moreover, the relationship between the $\beta$ and $\mathrm{PC}$ is shown in Figure 9(b) to investigate the change of $\beta$ with PC. It was observed that $\beta$ increases with a gradient equal to that of the PC increase independent of $s_{\mathrm{r}}$ as $\beta=\delta \cdot \mathrm{PC}^{\varepsilon}+\beta_{\text {pureGB }}$. These values of parameters changed as $s_{\mathrm{r}}$ changes. Based on observed relationships considering the effects of $D_{50 \mathrm{~GB}}$ and PC, $\beta$ can be calculated as

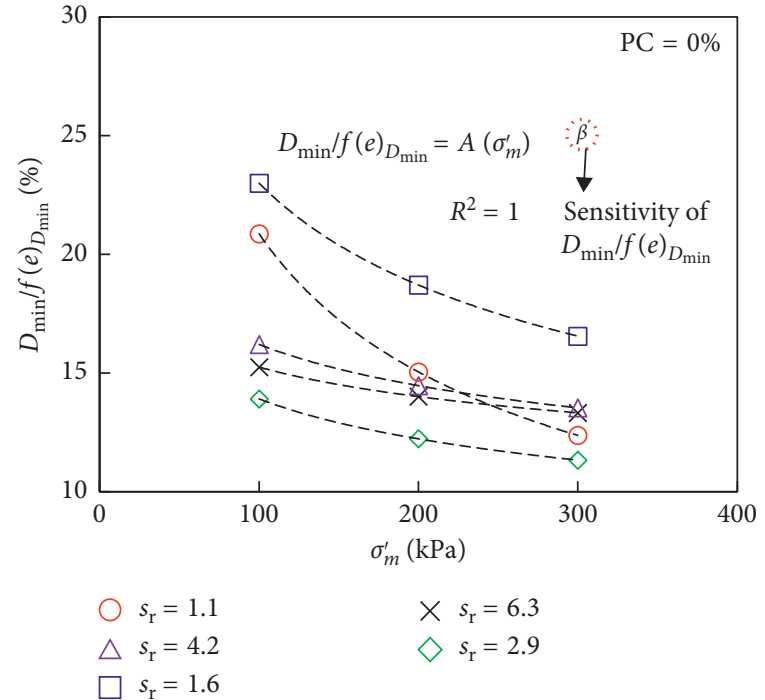

FIGURE 8: Variation of $D_{\text {min }}$ normalized by packing with confinement $\left(\sigma_{m}^{\prime}\right)$.

$$
\beta=-\gamma \cdot \ln D_{50 \mathrm{~GB}}+\delta \cdot \mathrm{PC}^{\varepsilon},
$$

where the value of parameter $-\gamma$ is -0.14 and the values of parameters $\delta$ and $\varepsilon$ are 0.02 and 0.38 , respectively, in this study.

4.2.3. Effect of Size Ratio $\left(s_{r}\right)$ and PB Content (PC) on $D_{\min }$. Coefficient $\alpha$ of the first term in equation (8) is the $D_{\min }$ of the pure GB when there is no effect of the packing under unity confinement (i.e., $\sigma_{m}^{\prime}=1 \mathrm{kPa}$ ). To evaluate the $D_{\min }$ of mixtures according to $s_{\mathrm{r}}$, an experiment was performed by changing the $D_{50}$ of pure $\mathrm{GB}$ (i.e., $\mathrm{PC}=0 \%$ ). Figure 10 shows 


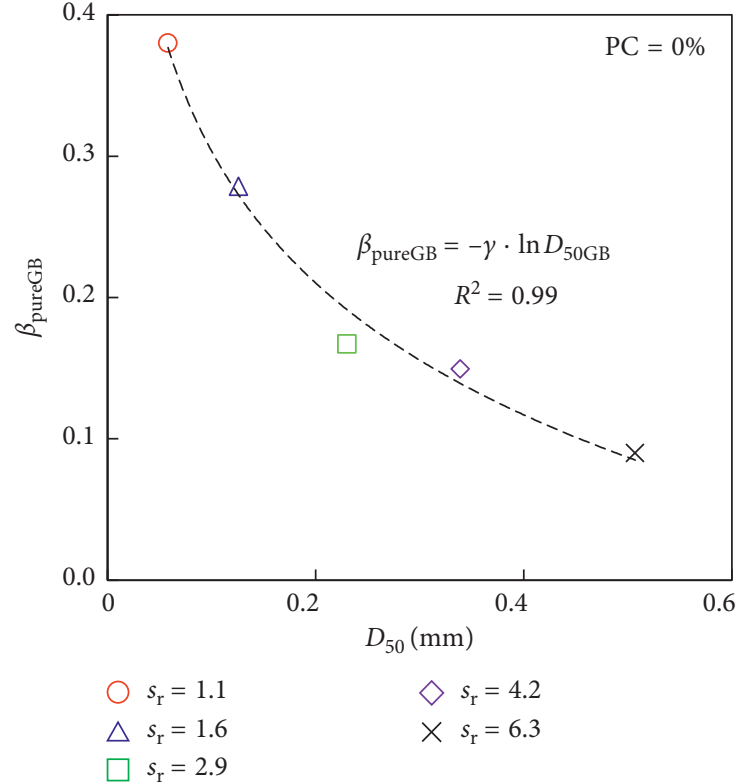

(a)

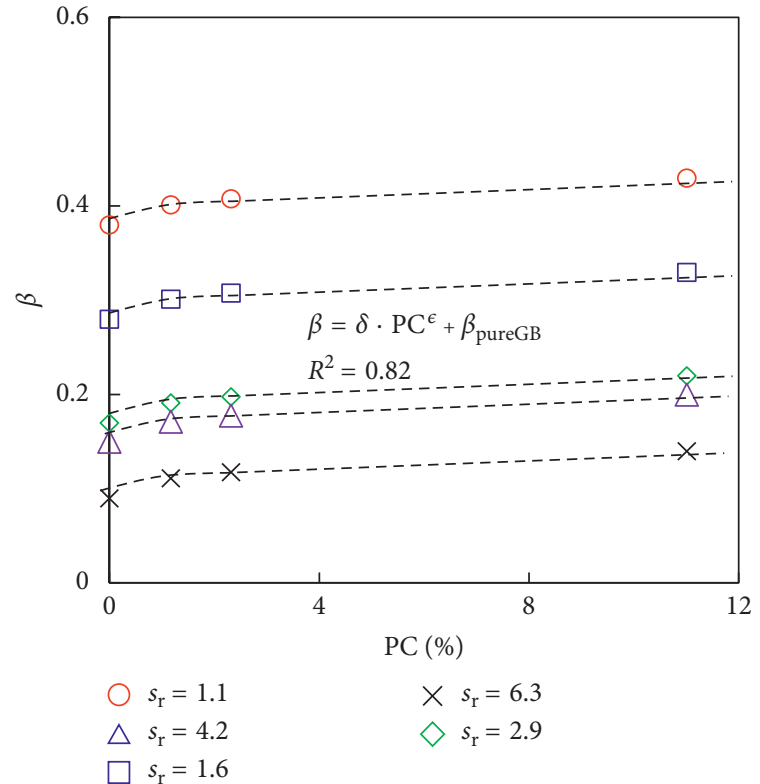

(b)

Figure 9: Variation of $\beta$ exponent according to (a) effect of median particle size of GB $\left(D_{50 \mathrm{~GB}}\right)$ and (b) effect of PC content.

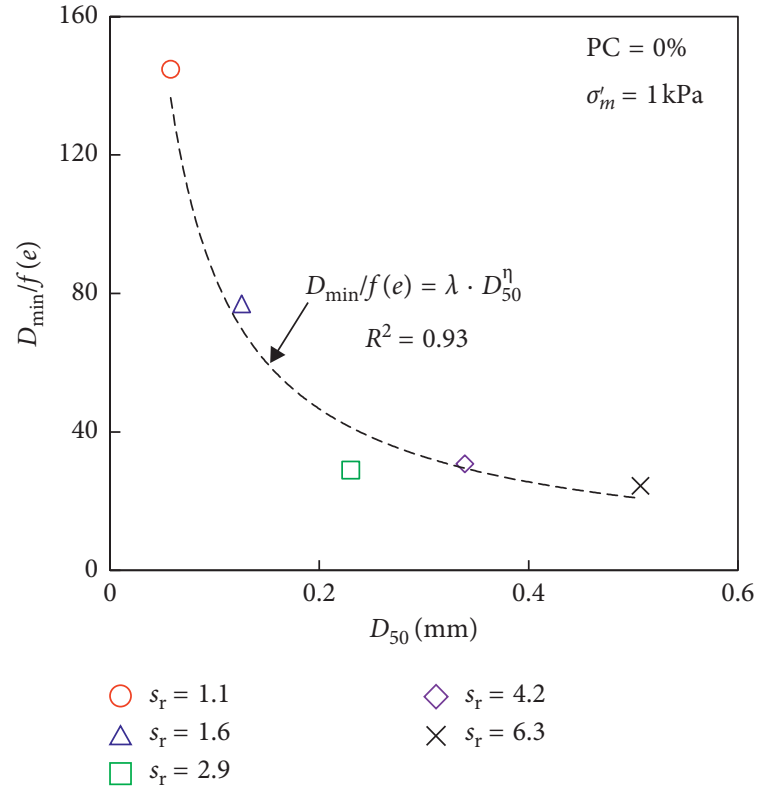

FIgURE 10: Variation of $D_{\min } / f(e)_{D_{\min }}$ with $D_{50 G B}$.

the relationship between $D_{\min } / f(e)_{D_{\min }}$ and $D_{50 \mathrm{~GB}}$. The value of $D_{\min } / f(e)_{D_{\min }}$, i.e., $\alpha$ value, under $\sigma_{m}^{\prime}=1 \mathrm{kPa}$ decreased with an increase of $D_{50 \mathrm{~GB}}$ as $D_{\min } / f(e)_{D_{\min }}=\lambda \cdot D_{50 \mathrm{~GB}}^{\eta}$.

The effect of PC on $D_{\min }$, i.e., $\left(D_{\min } / f(e)_{D_{\min }}-\alpha\right)$, which is $D_{\min }$ eliminated with the influence of $\alpha$, is indicated with the increase of PC under the $\sigma_{m}^{\prime}=1 \mathrm{kPa}$, as shown in Figure 11 . It was observed that $D_{\min }$ linearly increased with an increase of PC as $f(\mathrm{PC})=\mu \cdot \mathrm{PC}$. Note that parameter $\mu$

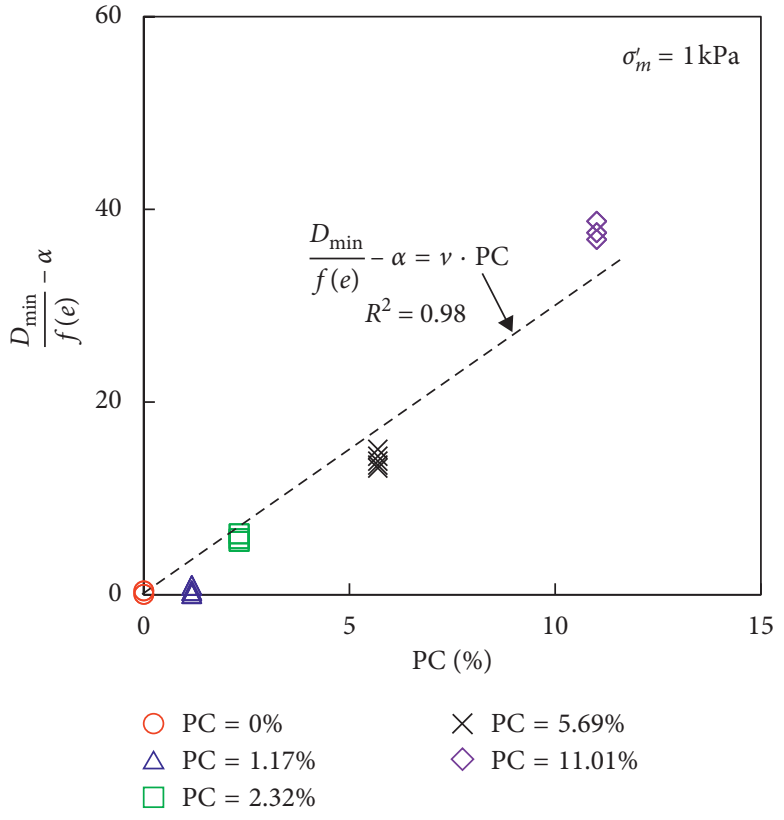

FIGURE 11: $D_{\min }$ of GB material without the effect of packing.

is the gradient for the relationship between $D_{\min }$ of the unit confining pressure and PC, and its value is 4.3 , in this study. To validate the proposed equation, the experiment with $\mathrm{PC}=5.69 \%$ was additionally conducted and the result agreed well with the suggested relation as shown in Figure 11. Consequently, we confirmed that $D_{\min }$ tends to increase because when a relatively rigid soft material such as polyurethane is mixed with a rigid material, the contact of 


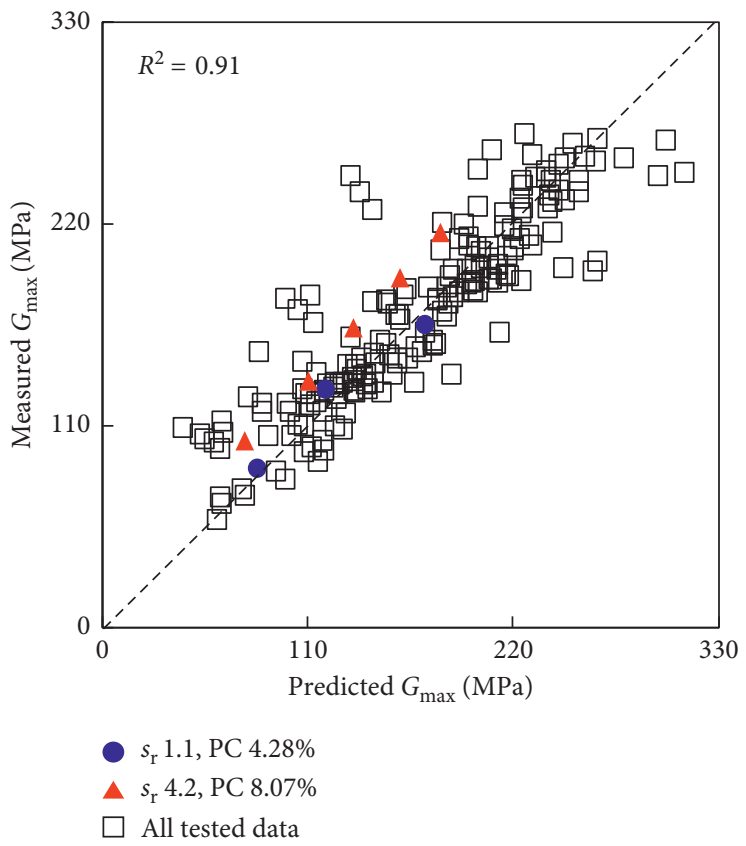

FIgURE 12: Comparison between measured $G_{\max }$ and predicted $G_{\max }$.

the large particles is inhibited and the plasticity is increased as the content thereof increases.

\section{Formulation of Practical Equations for Estimating $\mathbf{G}_{\max }$ and $D_{\text {min }}$}

5.1. Formulation for $G_{\max }$ with Factors. By investigating the various factors, such as confining pressure, void ratio, and particle size, affecting the $G_{\max }$ of spherical mixtures, we proposed equations (5)-(7). By substituting these equations into equation (4), the formulation for estimating the $G_{\max }$ on the spherical material mixture of noncohesive plastic can be expressed as

$$
\begin{aligned}
G_{\max }(\mathrm{MPa})= & (A+d \cdot \mathrm{PC}) \cdot \frac{\left(E-e_{\mathrm{ig}}\right)^{2}}{\left(1+e_{\mathrm{ig}}\right)} \cdot \frac{\left(\sigma_{m}^{\prime}\right)^{n c \cdot \mathrm{PC}+a \cdot D_{50 \mathrm{~GB}}^{b}}}{1000} \\
= & (7.19-53.85 \cdot \mathrm{PC}) \cdot \frac{\left(2.17-e_{\mathrm{ig}}\right)^{2}}{\left(1+e_{\mathrm{ig}}\right)} \\
& \cdot \frac{\left(\sigma_{m}^{\prime}\right)^{0.6 \cdot D_{50 G \mathrm{~B}}^{0.06} \cdot 0.01 \cdot \mathrm{PC}}}{1000} .
\end{aligned}
$$

The first term of the proposed equation represents the $G_{\max }$ of material per $\sigma_{m}^{\prime}$ when there is no effect on the packing. Parameters $A$ and $d$ are fitting parameters that change according to the composition of the material. Since the stiffness of PB is much smaller than that of GB, the stiffness of the whole mixture decreases with increasing $\mathrm{PB}$ contents. The second term indicates the effect of the packing condition on $G_{\max }$. It was shown that $e_{\mathrm{ig}}$ is in good agreement with $G_{\max }$ compared to $e$. $E$ is the shape factor for round particle and is used as 2.17. Given that the increment rate of confining pressure, the $n$ was associated with the change of $D_{50 \mathrm{~GB}}$ and PC. The $n$ can be obtained as $0.06 \cdot D_{50 \mathrm{~GB}}^{0.06} \cdot 0.01 \cdot \mathrm{PC}$. Figure 12 compares the measured $G_{\max }$ and the $G_{\max }$ predicted by equation (11). The predicted data agreed well with the measured data. The coefficient of determination was very high, $R^{2}=0.91$. In addition, to validate the proposed equation, extra experiments for two conditions ( $\mathrm{PC}=4.28 \%$ in $s_{\mathrm{r}}=1.1$ and $\mathrm{PC}=8.07 \%$ in $s_{\mathrm{r}}=4.2$ ) are additionally conducted and their results fitted well with the proposed equation as shown in Figure 12.

5.2. Formulation for $D_{\min }$ with Factors. To corroborate the constant $C$ in the packing function obtained by multivariable regression analysis, $C$ was estimated by back analysis using the $D_{\min }$ values for all tested mixtures with the confining pressure $(\alpha+f(\mathrm{PC}))$ and $\beta$ in equation (8). As shown in Figure 13(a), $C$ was about 0.042 in all conditions of $s_{\mathrm{r}}$ and PC. Therefore, the result obtained from multivariable regression analysis to calculate the packing function is appropriate.

By substituting equations (9) and (10) considering the effects for packing condition and confining pressure with $\mathrm{PB}$ contents (PC) on $D_{\min }$ of spherical mixtures into equation (8), equation (12) to predict the $D_{\min }$ of a spherical material mixture of noncohesive plastic can be suggested as

$$
\begin{aligned}
D_{\min }(\%)= & \left(\lambda \cdot D_{50 \mathrm{~GB}}^{\eta}+\mu \cdot \mathrm{PC}\right) \\
& \cdot \frac{(C-e)^{2}}{(1+e)} \cdot \frac{\sigma_{m}^{\prime \beta}}{P_{\mathrm{atm}}} \cdot 100 \\
= & \left(11.54 \cdot D_{50 \mathrm{~GB}}^{-0.87}+4.3 \cdot \mathrm{PC}\right) \cdot \frac{(0.04-e)^{2}}{(1+e)} \\
& \cdot \frac{\sigma_{m}^{\prime-0.14 \cdot \ln D_{50 \mathrm{~GB}}+0.02 \cdot \mathrm{PC}^{0.38}}}{P_{\mathrm{atm}}} \cdot 100 .
\end{aligned}
$$




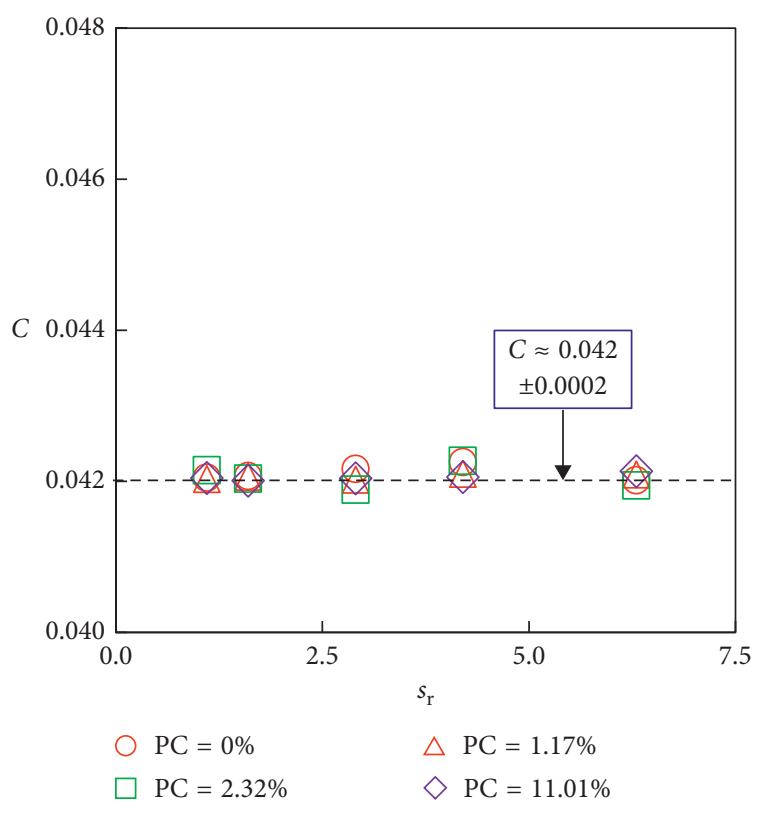

(a)

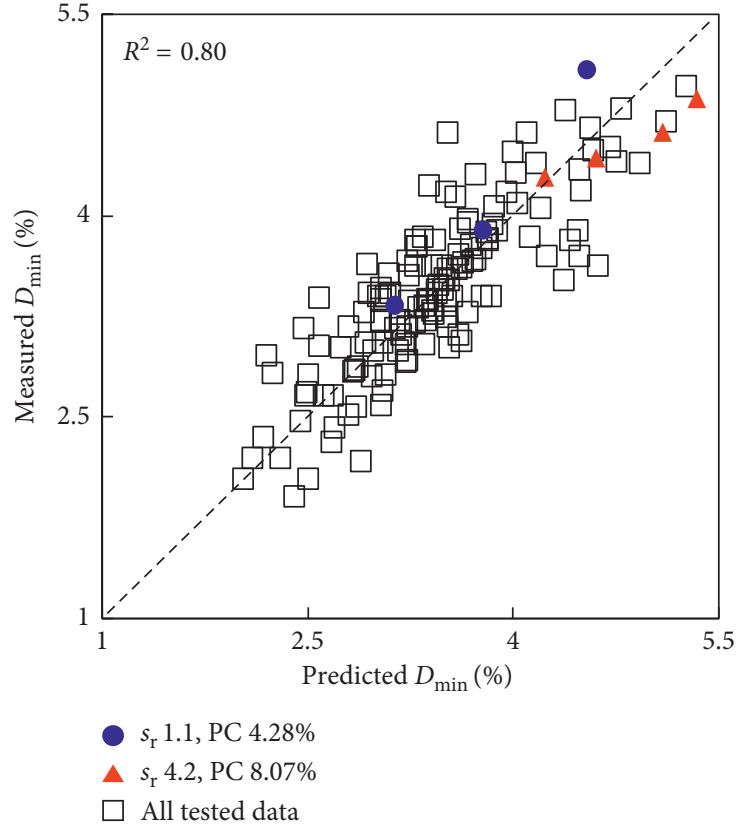

(b)

FIGURE 13: (a) Determination of packing constant with size ratio $\left(s_{\mathrm{r}}\right)$ and (b) comparison between measured $D_{\min }$ and predicted $D_{\text {min }}$.

The first term of proposed equation (12) represents the $D_{\min }$ of mixtures without the effect of packing under the unit confining pressure. Parameters $\lambda$ and $\mu$ depend on the composition materials, GB and PB. Since the $D_{\min }$ of GB is smaller than that of $\mathrm{PB}, D_{\min }$ of the mixture increased with increasing PC. The second term in equation (12) indicates the packing state when $D_{\min }$ is measured. In addition, because all particles, both large and fine particles, contribute to $D_{\text {min }}$, it was reasonable to use $e$ rather than $e_{\text {ig }}$ in this model, unlike the $G_{\max }$ model. Based on multivariable regression analysis and back analysis, the sharp factor $(C)$ of the packing function was identified as $C=0.04$. The $\beta$, indicating the slope of the change curve in $D_{\min }$ with confining pressure, was correlated with the change of $D_{50 \mathrm{~GB}}$ and PC. Figure 13(b) compares the measured $D_{\min }$ and predicted $D_{\min }$ by equation (12). As the same as $G_{\max }$, the extra experiments for two conditions $\left(\mathrm{PC}=4.28 \%\right.$ in $s_{\mathrm{r}}=1.1$ and $\mathrm{PC}=8.07 \%$ in $s_{\mathrm{r}}=4.2$ ) were additionally carried out to substantiate the proposed equation, and their data are included with all tested data, as shown in Figure 13(b). The predicted and measured data showed good agreement with the high coefficient of determination, $R^{2}=0.80$. Therefore, the applicability of the proposed equations could be confirmed based on this result.

Note that more experiments considering various contents of $D_{50}, \mathrm{PC}, e_{\mathrm{ig}}, e$, and $\sigma_{m}^{\prime}$ are needed to widely use the proposed equation.

\section{Conclusions}

Our experimental investigation carried out the parametric study for affecting $G_{\max }$ and $D_{\min }$ through the RC test. Based on the results, we proposed empirical equations to estimate $G_{\max }$ and $D_{\min }$ on the spherical mixture composed of the plastic and nonplastic materials. The following conclusions are drawn from this study:

(1) The most important parameters affecting the binary mixture composed of the plastic and nonplastic materials are polyurethane content (PC), mean confining effective stress $\left(\sigma_{m}^{\prime}\right)$, packing effect of void ratio $(e$ and $\left.e_{\mathrm{ig}}\right)$, particle-size ratio $\left(s_{\mathrm{r}}\right)$, and median grain size $\left(D_{50}\right)$.

(2) The effects of a void ratio in spherical mixtures (i.e., relative density reduction and an increase of confining pressure and the $\mathrm{PB}$ content) are dominant in the changes of $G_{\max }$ which showed a linear behavior with an increase of $e_{\mathrm{ig}}$. Moreover, the change of particle behavior caused by an increase of $s_{\mathrm{r}}$ to a larger particle size also affects $G_{\max }$.

(3) For $D_{\min }$ of the mixture, $e$ was used in the proposed prediction model because both the small particle (PB) and large particle (GB) contribute to $D_{\min }$ of the whole mixtures. Moreover, $n$ and $\beta$ that present the sensitivity of the confining pressure can be expressed as a function of $D_{50}$ and PC.

\section{Notations}

$G_{\max }: \quad$ Small-strain shear modulus

$D_{\min }: \quad$ Small-strain damping ratio

PB: $\quad$ Polyurethane beads

GB: $\quad$ Glass beads

PC: $\quad$ Nonplastic particle content

$e: \quad$ Global void ratio 
$e_{\mathrm{ig}}: \quad$ Intergranular void ratio

$s_{\mathrm{r}}\left(d_{\mathrm{L}} / d_{\mathrm{S}}\right):$ Particle-size ratio

$d_{\mathrm{L}}: \quad$ Median grain size of large particles (GB)

$d_{S}: \quad$ Median grain size of small particles (PB)

$\sigma_{m}^{\prime}: \quad$ Mean effective confining stress

$D_{50}$ : $\quad$ Median grain size

$f(e)$ : $\quad$ Function of $e$ on $D_{\min }$ and $D_{\min }$ in the mixtures

$f(\mathrm{PC})$ : $\quad$ Function of $\mathrm{PC}$ on $G_{\max }$ and $D_{\min }$ in the mixtures

$A$ and $\alpha: \quad G_{\max }$ and $D_{\min }$ of materials with no influence of void ratio when $\sigma_{m}^{\prime}=1 \mathrm{kPa}$

$n$ and $\beta$ : Sensitivity of the curve as $G_{\max }$ and $D_{\min }$ that depend on $\sigma_{m}^{\prime}$

$E$ and $C$ : Constant of packing for round particles on $G_{\max }$ and $D_{\min }$ in the mixtures

$a, b$, and Fitting parameters of $n$ value and $\beta$ value $-D_{50}$ $-\gamma: \quad$ curve

$c$ and $\delta, \varepsilon$, Fitting parameters of $n$ value and $\beta$ value-PC

$\varepsilon$ : $\quad$ curve

$\lambda$ and $\eta$ : $\quad$ Fitting parameters of $\alpha$ value

$\mu$ and $d$ : Fitting parameters of $\mathrm{PC}$ on $G_{\max }$ and $D_{\min }$ when $\sigma_{m}^{\prime}=1 \mathrm{kPa}$.

\section{Data Availability}

The data of small-strain dynamic properties used to support the findings of this study are included within the article.

\section{Conflicts of Interest}

The authors declare that they have no conflicts of interest.

\section{Acknowledgments}

This work was financially supported by the Ministry of the Interior and Safety as Earthquake Disaster Prevention Human Resource Development Project.

\section{References}

[1] F. E. Richart, Vibrations of Soils and Foundations, PrenticeHall, Englewood Cliffs, NJ, USA, 1970.

[2] H. B. Seed and I. M. Idriss, "Soil moduli and damping factors for dynamic response analysis," Report No. EERC 70-10, University of California, Berkeley, CA, USA, 1970.

[3] B. O. Hardin and V. P. Drnevich, "Shear modulus and damping in soils," Journal of the Soil Mechanics and Foundation Division, vol. 98, no. 7, pp. 667-692, 1972.

[4] T. Iwasaki, F. Tatsuoka, and Y. Takagi, "Shear moduli of sands under cyclic torsional shear loading," Soils and Foundations, vol. 18, no. 1, pp. 39-56, 1978.

[5] M. K. D. Lee, "DESRA-2: dynamic effective stress response analysis of soil deposits with energy transmitting boundary including assessment of liquefaction potential," Research Report, University of British Columbia, Vancouver, Canada, 1978.

[6] K. Zen, "Laboratory tests and in-situ seismic survey on vibratory shear modulus of clayey soils with various plasticities," in Proceedings of the 5th Japan Earthquake Engineering Symposium, pp. 721-728, Tokyo, Japan, November 1978.
[7] T. Kokusho, Y. Yoshida, and Y. Esashi, "Dynamic properties of soft clay for wide strain range," Soils and Foundations, vol. 22, no. 4, pp. 1-18, 1982.

[8] H. B. Seed, R. T. Wong, I. M. Idriss, and K. Tokimatsu, "Moduli and damping factors for dynamic analyses of cohesionless soils," Journal of Geotechnical Engineering, vol. 112, no. 11, pp. 1016-1032, 1986.

[9] S. H. Ni, Dynamic properties of sand under true triaxial stress states from resonant column/torsional shear tests, Ph.D. dissertation, The University of Texas at Austin, Austin, TX, USA, 1987.

[10] I. Ishibashi and X. Zhang, "Unified dynamic shear moduli and damping patios of sand and clay," Soils and Foundations, vol. 33, no. 1, pp. 182-191, 1993.

[11] K. M. Rollins, M. D. Evans, N. B. Diehl, and W. D. Daily III, "Shear modulus and damping relationships for gravels," Journal of Geotechnical and Geoenvironmental Engineering, vol. 124, no. 5, pp. 396-405, 1998.

[12] M. Vucetic, G. Lanzo, and M. Doroudian, "Damping at small strains in cyclic simple shear test," Journal of Geotechnical and Geoenvironmental Engineering, vol. 124, no. 7, pp. 585-594, 1998.

[13] K. H. Stokoe, S. K. Hwang, J. K. Lee, and R. D. Andrus, "Effects of various parameters on the stiffness and damping of soils at small to medium strains," in Proceedings of the International Symposium, Prefailure Deformation Characteristics of Geomaterials, vol. 2, pp. 785-816, Sapporo, Japan, September 1994.

[14] K. H. Stokoe, M. B. Darendeli, R. D. Andrus, and L. T. Brown, "Dynamic soil properties: laboratory, field and correlation studies," in Proceedings of the 2nd International Conference on Earthquake Geotechnical Engineering, vol. 3, pp. 811-845, Lisbon, Portugal, December 1999.

[15] J. C. Santamarina, A. Klein, and M. A. Fam, "Soils and waves: particulate materials behavior, characterization and process monitoring," Journal of Soils and Sediments, vol. 1, no. 2, p. 130, 2001.

[16] M. B. Darendeli, Development of a new family of normalized modulus reduction and material damping curves, Ph.D. dissertation, The University of Texas at Austin, Austin, TX, USA, 2001.

[17] J. Zhang, R. D. Andrus, and C. H. Juang, "Normalized shear modulus and material damping ratio relationships," Journal of Geotechnical and Geoenvironmental Engineering, vol. 131, no. 4, pp. 453-464, 2005.

[18] T. Wichtmann and T. Triantafyllidis, "Influence of the grainsize distribution curve of quartz sand on the small strain shear modulus $G_{\max }$," Journal of Geotechnical and Geoenvironmental Engineering, vol. 135, no. 10, pp. 1404-1418, 2009.

[19] T. Wichtmann and T. Triantafyllidis, "Effect of uniformity coefficient on $G / G_{\max }$ and damping ratio of uniform to wellgraded quartz sands," Journal of Geotechnical and Geoenvironmental Engineering, vol. 139, no. 1, pp. 59-72, 2013.

[20] T. Wichtmann, M. A. Navarrete Hernández, and T. Triantafyllidis, "On the influence of a non-cohesive fines content on small strain stiffness, modulus degradation and damping of quartz sand," Soil Dynamics and Earthquake Engineering, vol. 69, pp. 103-114, 2015.

[21] H. Choo and S. E. Burns, "Shear wave velocity of granular mixtures of silica particles as a function of finer fraction, size ratios and void ratios," Granular Matter, vol. 17, no. 5, pp. 567-578, 2015. 
[22] D. N. Humphrey and W. P. Manion, "Properties of tire chips for lightweight fill," in Proceedings of the Grouting, Soil Improvement and Geosynthetics, ASCE, vol. 30, pp. 1344-1355, Geotechnical Special Publication, New Orleans, LA, USA, February 1992.

[23] J. G. Zornberg, A. R. Cabral, and C. Viratjandr, "Behaviour of tire shred-sand mixtures," Canadian Geotechnical Journal, vol. 41, no. 2, pp. 227-241, 2004.

[24] A. Nakhaei, S. M. Marandi, S. Sani Kermani, and M. H. Bagheripour, "Dynamic properties of granular soils mixed with granulated rubber," Soil Dynamics and Earthquake Engineering, vol. 43, pp. 124-132, 2012.

[25] A. Anastasiadis, K. Senetakis, and K. Pitilakis, "Small-strain shear modulus and damping ratio of sand-rubber and gravelrubber mixtures," Geotechnical and Geological Engineering, vol. 30, no. 2, pp. 363-382, 2012.

[26] N. Zhang, Z. Wang, Y. Jin, Q. Li, and X. Chen, "Experimental study on dynamic properties of sand-rubber mixtures in a small range of shearing strain amplitudes," Journal of Vibroengineering, vol. 19, no. 6, pp. 4378-4393, 2017.

[27] G. Gazetas, "Chapter 15: foundation vibrations," in Foundation Engineering Handbook, H.-Y. Fang, Ed., pp. 553-593, Chapman \& Hall, London, UK, 2nd edition, 1991.

[28] B. O. Hardin and F. E. Richart, "Elastic wave velocities in granular soils," Journal of the Soil Mechanics and Foundations Division, ASCE, vol. 89, no. 1, pp. 33-65, 1963.

[29] D. C. F. Lo Presti, M. Jamiolkowski, O. Pallara, A. Cavallaro, and S. Pedroni, "Shear modulus and damping of soils," Géotechnique, vol. 47, no. 3, pp. 603-617, 1997.

[30] T. Iwasaki and F. Tatsuoka, "Effects of grain size and grading on dynamic shear moduli of sands," Soils and Foundations, vol. 17, no. 3, pp. 19-35, 1977.

[31] P. Alba, K. Baldwin, V. Janoo, G. Roe, and B. Celikkol, "Elastic-wave velocities and liquefaction potential," Geotechnical Testing Journal, vol. 7, no. 2, pp. 77-88, 1984.

[32] Z. Y. Feng and K. G. Sutter, "Dynamic properties of granulated rubber/sand mixtures," Geotechnical Testing Journal, vol. 23 , no. 3, pp. 338-344, 2000.

[33] B. O. Hardin and V. P. Drnevich, "Shear modulus and damping in soils: measurement and parameter effects (Terzaghi lecture)," ASCE Journal of Geotechnical and Geoenvironmental Engineering, vol. 98, no. 6, pp. 603-624, 1972.

[34] F. Tatsuoka, T. Iwasaki, and Y. Takagi, "Hysteretic damping of sands under cyclic loading and its relation to shear modulus," Soils and Foundations, vol. 18, no. 2, pp. 25-40, 1978.

[35] N. Q. Khouri, "Dynamic properties of soils," Master's thesis, Department of Civil Engineering, Syracuse University, Syracuse, NY, USA, 1984.

[36] R. H. Borden, L. Shao, and A. Gupta, "Dynamic properties of Piedmont residual soils," Journal of Geotechnical Engineering, vol. 122, no. 10, pp. 813-821, 1996. 


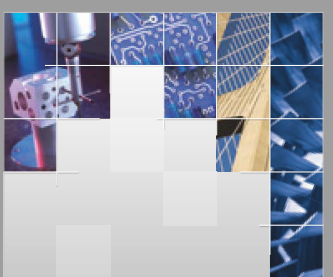

\section{Enfincering}
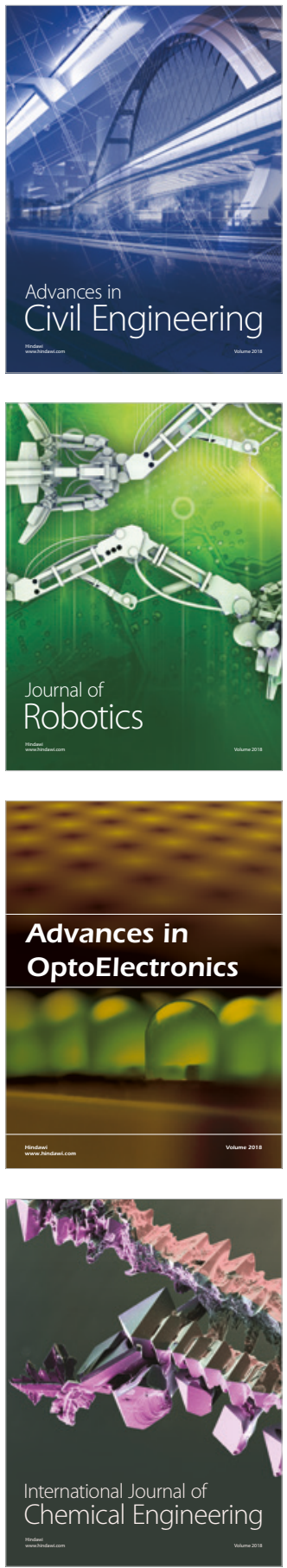

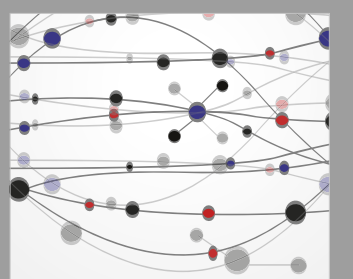

\section{Rotating \\ Machinery}

The Scientific World Journal

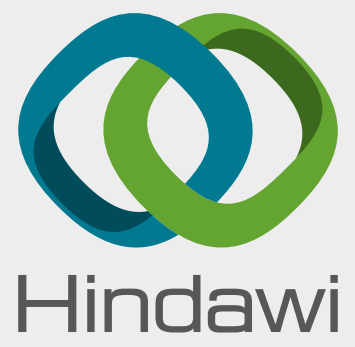

Submit your manuscripts at

www.hindawi.com
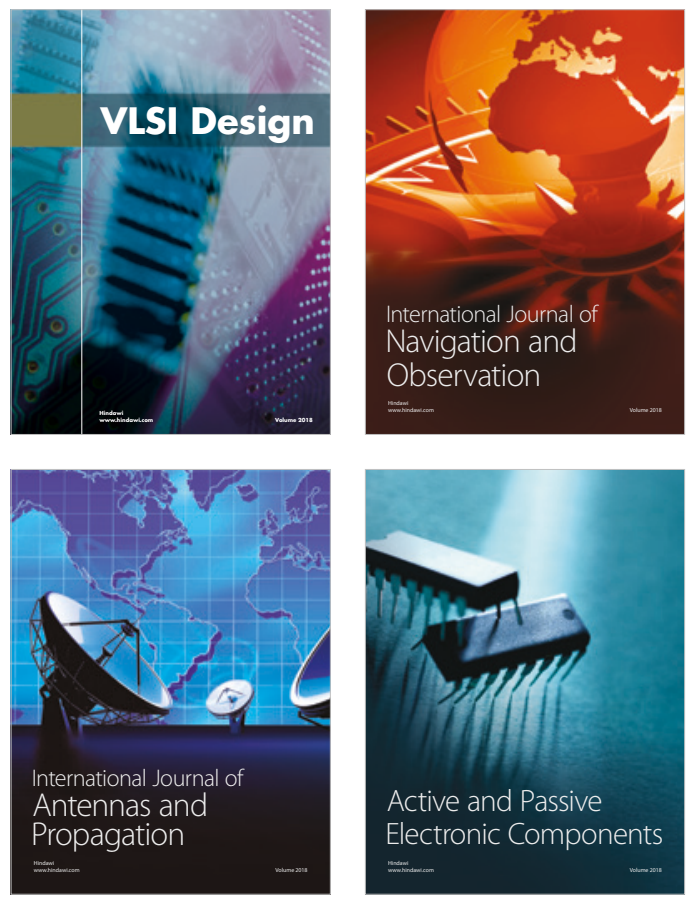
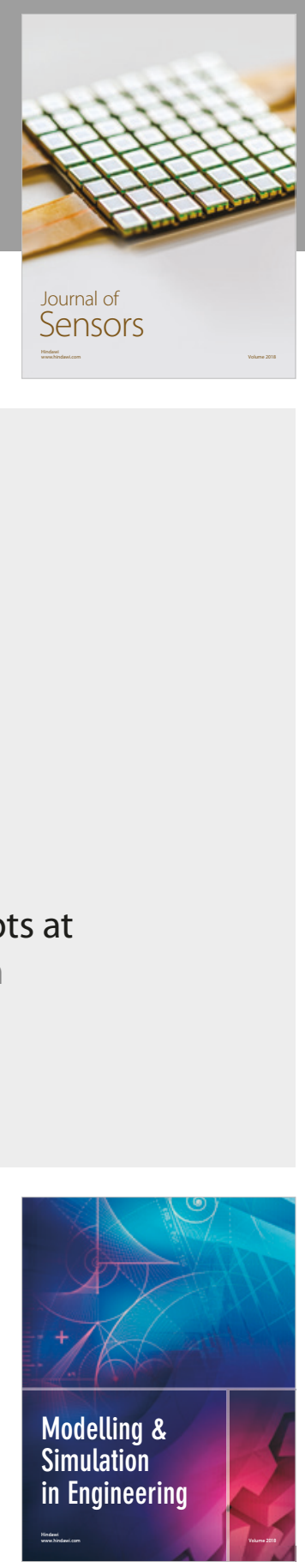

\section{Advances \\ Multimedia}
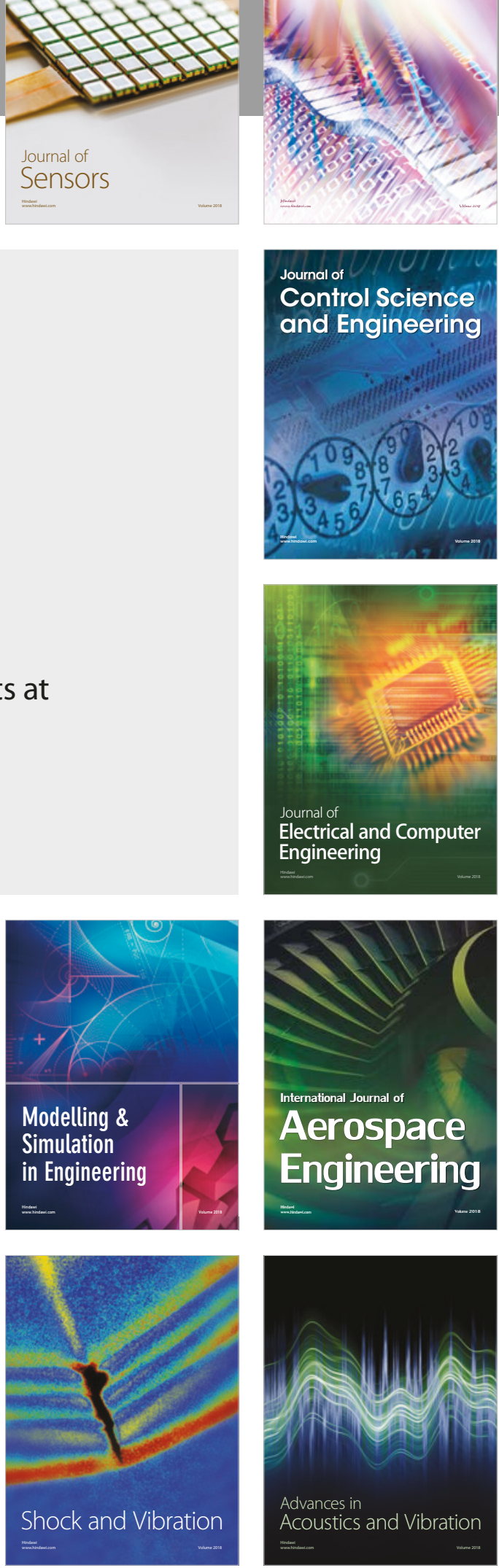